\title{
The relationship between EFL instructors' knowledge of mediation and their classroom practice
}

Tahriri, Abdorreza $\measuredangle$

University of Guilan, Iran (atahriri@gmail.com)

Rezaee-Manesh, Najafquli

University of Guilan, Iran (Rezarezaee49@ gmail.com)

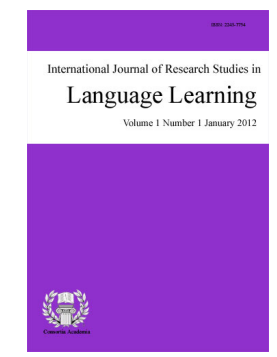

ISSN: 2243-7754 Online ISSN: 2243-7762

OPEN ACCESS

\section{Abstract}

The present mixed-method study aimed at investigating to what extent EFL instructors in junior and senior high schools, institutes, and universities in Iran have knowledge of mediation and how often they implement their knowledge of mediation in their classes. To this end, 181 instructors (101 males and 80 females) participated in the study. Out of 181 participants, 72 of them took part in the oral interviews as well. To collect the data, close-ended questionnaire and oral interview were used and to analyze the data, descriptive statistics, and Chi-square were run. The findings revealed that there is a relationship between the instructors' knowledge of mediation and their practice in their classes but their practice of mediation does not totally reflect their knowledge of mediation. Moreover, the analysis of oral interviews revealed that making the task significant culminates in fostering learners' motivation and learning, and to make a task significant, the participating instructors suggested explanation, engagement, use of real world materials, and making the task goal-oriented. In terms of transcendence, it was revealed that from the instructors' view, it is possible to help learners transfer their learnt knowledge to new situations. Use of real world material, explaining how to transfer, and bridging the known to unknown are strategies that were suggested for promoting transcendence. The instructors' awareness of when, where, and how to intervene in the learning process of learners would lead to promotion of learning and teaching.

Keywords: mediation; knowledge; practice; instructors; EFL 


\section{The relationship between EFL instructors' knowledge of mediation and their classroom practice}

\section{Introduction}

With the emphasis on facilitating learner autonomy and life-long education in recent years, it has become significant that teachers, instead of knowledge dissemination and tight control of learners' behavioral changes, should empower them to self-control, and self-regulate their learning and become more active thinkers and problem-solvers. To do so, the role of teachers in providing the conditions for learners in order to reach self-regulation is very significant and vital. To ensure learner-centered education in English as a foreign language (EFL) context, teachers should highlight the development of students' independence and autonomy by adjusting their roles to new needs of learners and current trends of modern educational system (Ting, 1987; Yang, 2005; $\& Y e, 2007)$. Seng, Pou, and Tan (2003) stressed that it is necessary for teachers to play their role as a mediator instead of a disseminator in the language classroom since the value of adult mediation in children's learning can never be overemphasized.

Feuerstein and Feuerstein (1991, p. 7) defined mediated learning experience (MLE) as a "quality of interaction between the organism and its environment". Lantolf and Thorne (2006) also defined mediation as the process through which human beings apply culturally constructed artifacts, concepts, and activities to regulate the material world of their own and other social and mental activities. Artifacts are not facilitative by themselves and they operate the mediative role through repeated use by the learners. Based on Mediation Theory (MT) by Feuerstein (1980, 1990, 1991), teachers' role regarding teaching and instructing learners in comparison with traditional methods in which the concentration was on authority and centrality of the teachers and passivity of the leaners, has changed and it has been replaced by mediative role of teachers that is believed to play a paramount role in the learners' learning experience. According to the MT, the responsibility of teachers and instructors in different levels of education is not to provide the learners with ready-made and prepackaged knowledge and information. Instead, teachers and instructors should be present while the learners are tackling with the problems in order to provide direction and on-time intervention to move them toward their potential. Thus, teachers in the role of mediators should attend in all phases of learning so that they can assess the students' mental processing while they are busy doing a challenging task and this is the point that teachers can hardly achieve through psychometric tests since by application of psychometric tests, they are able to measure current level of knowledge (Williams \& Burden, 1997).

Concerning the significance of the study, teachers, learners, and curriculum designers are the major stakeholders in this regard. Teachers might come to the point that learners are not benchmark beings who should be only filled with knowledge on the basis of their predetermined capacity. Instead, due to their elastic cognitive structure, the learners are able to take the responsibility of learning provided that their teachers assign them with doable tasks and scaffold them to the extent that it stimulates them to move on and then they should draw back strategically to put the learners into challenge. Another important significance and contribution of the present study relates to the empowerment of teachers with on-time intervention which in turn fosters teachers' expertise in teaching and task selection.

Although studies that were carried out in EFL context are abundant, none of those studies were conducted in an EFL context such as Iran. Another point is that this study included EFL teachers in institutes, universities, junior and senior high schools while Cheng's $(2011,2012)$ studies only included teachers of high school in one province. The present study extended the scope of study and tried to collect data through oral interview and closed-ended questionnaires from different teachers of several provinces in Iran. Researchers such as Cheng $(2011,2012)$ claimed that EFL instructors in China are unable to perform their true mediative roles due to their misconception in terms of mediation. As such, the findings and results of other studies might not be transferable 
The relationship between EFL instructors' knowledge of mediation and their classroom practice

to an EFL context such as Iran which has its own cultural and contextual characteristics.

The significance of the study is the possibility of revealing the gap that might exist between what the instructors say and what they do in their classroom context. Revealing the factors that make them not to be able to mediate in a consistent and acceptable way in their own situation of learning will provide great help to teachers, policy makers, and educationalists. After determining the main causes of absence or presence of mediation, they are able to provide their teachers due education and relevant training in order to make them more competent and up to date. Based on the aforementioned arguments, the sources of teachers' potential success and failure are to be explored in the present study in line with mediation theory. The aim is to measure mediative knowledge of teachers in junior and senior high school, institutes, and universities in Iran and to investigate the teachers' practice inside their teaching contexts.

As such, the present study intends to answer the following questions:

$>\quad$ RQ1. Is there any relationship between EFL teachers' knowledge of mediation and their classroom practice?

$>\quad$ RQ2. What is the relationship between making a task significant and motivation in the perspective of EFL instructors in different settings in Iran?

$>$ RQ3. What do EFL instructors think of transcendence?

\section{Literature Review}

Sociocultural perspectives regarding development and learning were originated and shaped by Vygotsky (1978) and were applied by him in his studies. He was mainly influenced by Russian revolution and Marxist psychology which believed that individuals should scarify their personal goals for the sake of larger community. Vygotsky firmly announced that socialization and collectivism are essential in actualization of learners' potentials. He also stressed that knowledge is not a fixed and motionless phenomenon that like traditional view is conveyed unilaterally by the teachers and only teachers should have control over it. Moreover, he claimed that knowledge is a social event and is created when learners engage in interaction with others. To accentuate on social arena responsible for learners' learning, he never decentralizes teachers but he views teachers' role from sociocultural perspectives which considers teachers as people who know when to intervene in scenes of the learning. Therefore, the teachers are charged with responsibilities to select appropriate and relevant task in which first, social knowledge is being created and then it is assimilated in individuals' or learners' cognitive system (Daniels, 1994).

Vygotsky (1978) and Feuerstein $(1980,1990,1991)$ rejected the beliefs that learners should be categorized on the basis of their disabilities and IQ rates. They believed that all children are educable with appropriate intervention of teachers and instructors and they also believed that development in children is similar regardless of whether they are normal or handicapped; therefore, educationalists and methodologists should take this fact into consideration and they should take a holistic view about the act of learning. Williams and Burden (1997) claimed that sociocultural theory (SCT) opposes the idea of the disconnected teaching of skills. They argued that meaning should constitute the central aspects of any unit of study. Any unit of study should be presented in all its complexity and in their ideas based on SCT, separate knowledge and skill presentation does not suffice any more. SCT emphasized the importance of what the learner brings to any learning situation and it considered learners as active meaning-makers and problem-solvers. It emphasized the dynamic nature of the interplay between teachers, learners and tasks, and it also views learning as a phenomena which arise out of interactions with others.

Swain (2000) argued that language learning involves learning how to use language to mediate language learning. To achieve this state, the teacher should establish verbal interaction which might be in shape of monologic or dialogic. In Swain's point of view, both of them are conductive and beneficial, but the priority and 
Tahriri, A. \& Rezaee-Manesh, N.

centrality is with dialogic interaction because the dialogic interaction would create a context where the novice would actively participate in social interaction and as a result, the mediator would find opportunity to support the novice while struggling with the task.

Tzuriel (2000) interprets Feuerstein's MLE as a process during which teachers place themselves between the individual and the set of stimuli. This mediator then mediates the stimuli to the child. This may include various strategies such as changing the frequency or order of the stimuli presented, relating them to contexts that are familiar to the individual, and so forth. It is the mediator's role to motivate the individual by arousing their curiosity, vigilance and challenge. In other words, the mediator, in effect, tries to improve the individual's cognitive functions that are required for them to determine the temporal, spatial and cause-effect relationship. It is hoped that the individual would gradually internalize these motivation strategies to become part of the change mechanism within the individual. These strategies should allow the individual to develop later on, independently, to gain meaning from learning experiences, to be able to self-mediate in similar but new learning situations and ultimately be able to actively modify their own cognitive systems. Indeed, "mediation theory has played a central role in social constructivist framework" (Sun, 2005, p. 6).

\section{Method}

\subsection{Participants}

The total participants of this study consisted of 181 EFL teachers in junior and senior high schools, language institutes, and universities in Guilan province, Rasht, Iran and some other provinces in Iran. Out of 181 participants, 162 (90\%) were from Guilan province where the study was carried out. Although the majority of teachers were almost from all towns of Guilan province, 19 (10\%) teachers from Tehran, Markazi, Ardabil, Mazandaran, and Khorasan provinces also participated in this study. To sample the participants, both cluster random and convenience sampling were used. Cluster random sampling was used for the participants who were in Guilan province.

Before sampling randomly, all the towns of Guilan province were selected and then, twelve towns of the province were selected randomly and then from twelve randomly selected towns, the data were collected from all the participants who agreed to participate in the study. To collect data from other already-mentioned provinces, the data were collected from anyone who was accessible (convenience sampling). To compensate the researcher's absence in other provinces, English teachers and even MA teachers were used to avoid possible problems in the process of data collection. From 181 teachers, $80(44 \%)$ were males and $101(56 \%)$ were females. Out of 181, $72(40 \%)$ agreed to take part in the oral interview. Out of 72 interviewees, $16(22 \%)$ institute teachers, $36(50 \%)$ senior and junior high school teachers, $20(28 \%)$ university teachers took part in oral interview.

Table 1 summarizes the information concerning the frequency and percentage of the participants:

\section{Table 1}

Frequency and Percentage of the Participants across Instruments, Provinces, and Gender

\begin{tabular}{lcc}
\hline \multicolumn{1}{c}{ Participants } & Frequency & Percentage \\
\hline Total participants & 181 & $100 \%$ \\
Number of participants in closed questionnaires & 181 & $100 \%$ \\
Number of participants in oral interview & 72 & $40 \%$ \\
Number of participants from Guilan province & 162 & $90 \%$ \\
Number of participants from Other provinces & 19 & $10 \%$ \\
Females & 101 & $56 \%$ \\
Males & 80 & $44 \%$ \\
\hline
\end{tabular}




\subsection{Instruments}

To gather the data, several instruments were used to triangulate the findings:

Mediation Questionnaire - The close-ended Questionnaire is composed of three separate parts. The first part starts with a consent form which takes the confidentiality issues and purpose of study into the account. Under this consent form, contact and demographic parts are also included. The second part aims at measuring the teachers' beliefs of mediation. This part consists of twelve items which aim to determine the importance of mediation from the perspectives of teachers. Above this questionnaire, there are numbers from 1 to 5 that showed how important the twelve mediative features were from the perspectives of the participants. This value starts from Not at all important to very important. Part three that consists of twelve items aims to assess how often the teachers think they carry out each of the mediative functions. The second twelve items have the same wording and items and in this regard there are no differences from the first twelve items but the function of the first and the second twelve items are different from each other. To prevent any possible problem, some instructions were added on the top of each questionnaire.

To avoid possible problems, first the two questions of oral interview were given to five participants and they were asked about wording, content, and possible ambiguities. Based on their answers, the original version was modified to make the questions informative in order to elicit what was going inside the participants' mind regarding their mediative roles. Regarding the close-ended questionnaire, although its reliability was already established by Warren (1995), the reliability of the questionnaire was calculated again because cross-cultural difference might have an impact on the reliability of the questionnaires. Therefore, the questionnaire was piloted with 51 participants. The Cronbach alpha reliability of the questionnaire was found to be .91\% (See the following table):

\section{Table 2}

Reliability of the Close-ended Questionnaire

\begin{tabular}{ccc}
\hline Number of participants & Number of items & Cronbach's reliability \\
\hline 51 & 24 & .91 \\
\hline
\end{tabular}

Oral interview Items - The Oral interview items were designed based on existing literature. To this end, they consisted of two questions which were used to investigate EFL instructors' perspectives towards significance and transcendence. The two afore-mentioned questions were designed according to Williams and Burden (1997) and Warren's (1995) closed-ended questionnaire.

\subsection{Procedure}

The questionnaire was designed initially in English and then it was translated into Persian in order to avoid the possible problems for interpretation of English version. The validity of translation was checked through back translation of the English version. To this end, the researcher asked three instructors and three EFL teachers to review the accuracy of the translation. After the review, the researcher modified some parts of it. The questionnaire was piloted first to ensure its reliability and possible problems that could emerge in the operationalization phase of the study. To this end, five English teachers out of the whole population were selected and then they were assigned to complete the questionnaire with the circumstances similar to the main phase of the study. No intervening problems were noticed and none was reported by the five participants of the pilot study. Because the five teachers had some information in terms of the questionnaire, they were excluded from the sample and no data were collected from them again. Except adding one word in parentheses to explain the meaning of the word [foster], no other change in the body of questionnaire was made; however, on the top of each two part, some instructions were given. After this phase, the questionnaire was distributed among fifty-one teachers and its reliability was calculated and when the results revealed high reliability, it was distributed among the target participants of the study. To distribute the questionnaires among junior and senior high school teachers, 
Tahriri, A. \& Rezaee-Manesh, N.

language institute and university instructors in Guilan province, the researchers asked their permission and requested them to complete them. For those who were in other provinces, the questionnaires were emailed to the colleagues.

\subsection{Data analysis}

To analyze the collected data through oral interview, both qualitative and quantitative approaches of data analysis were utilized. After collecting the data through questionnaires and codifying the data, all the quantitative data were entered to SPSS (Version 19). Descriptive statistics including frequencies, mean, standard deviation, and range were first calculated and then they were reported, too. Chi-square also was run to compare junior and senior high school teachers with institute and university teachers' practices. To compare their knowledge of mediation with their practice, Chi-square was run as well. To analyze the data collected through oral interview, both qualitative and quantitative analysis were used. To this end, the gathered data were studied carefully and then all the factors mentioned by the participants were marked and finally, all those factors were counted to see what mediative features teachers in different setting applied. To do so, frequency of the factors were also calculated. After calculating the frequency, the percentage of the factors were calculated and then based on frequency and percentage of the qualitative data, those factors that had the highest percentage and frequency were elicited and were interpreted. In qualitative analysis of the data, description, interpretation, and comparison were applied.

\section{Results}

Table 3 represents the descriptive statistics, percentage, and chi-square of knowledge and practice of mediation as far the closed questionnaire is concerned:

\subsection{Results of Closed Questionnaire}

\section{Table 3}

Results of Descriptive Statistics, Percentage, and Chi-square of Knowledge and Practice of Mediation

\begin{tabular}{|c|c|c|c|c|c|c|c|c|c|c|c|}
\hline \multirow{2}{*}{$\begin{array}{l}\text { Knowledge from } \mathrm{A} 1 \text { to } \mathrm{A} 12 \text { and } \\
\text { practice from } \mathrm{B} 1 \text { to } \mathrm{B} 12\end{array}$} & \multirow{2}{*}{$M$} & \multirow{2}{*}{$S D$} & \multicolumn{5}{|c|}{ Percentage } & \multirow{2}{*}{$\begin{array}{c}\text { Chi } \\
\text { square }\end{array}$} & \multirow{2}{*}{$d f$} & \multirow{2}{*}{$\begin{array}{l}\text { Asymp } \\
\text { sig }\end{array}$} & \multirow{2}{*}{ Range } \\
\hline & & & 1 & 2 & 3 & 4 & 5 & & & & \\
\hline Clear instruction A1 & 4.48 & .67 & .6 & $\ldots$ & 6.6 & 36.5 & 56.4 & 82.34 & 9 & .000 & 4 \\
\hline Clear instruction B1 & 4.35 & .76 & $\ldots$ & 2.8 & 9.4 & 37.6 & 50.3 & & & & 3 \\
\hline Reason of doing an activity $\mathrm{A} 2$ & 3.91 & .82 & .6 & 3.9 & 23.8 & 47 & 24.9 & 260.14 & 16 & .000 & 4 \\
\hline Reason of doing an activity B2 & 3.84 & .90 & 6 & 5.5 & 29.8 & 37.0 & 27 & & & & 4 \\
\hline Explain how to do an activity A3 & 3.97 & .78 & .. & 3.3 & 21.5 & 49.2 & 26 & 112.89 & 9 & .000 & 3 \\
\hline Explain how to do an activity B3 & 3.87 & .84 & $\ldots$ & 5.0 & 27.6 & 42.0 & 25.4 & & & & 3 \\
\hline Feeling of confidence A4 & 4.43 & .70 & .. & 1.1 & 8.8 & 35.9 & 54.1 & 26.95 & 9 & .001 & 3 \\
\hline Feeling of confidence B4 & 4.23 & .77 & $\ldots$ & 1.7 & 15.5 & 40.3 & 42.5 & & & & 3 \\
\hline Teaching strategies A5 & 4.31 & .72 & .. & 6 & 13.8 & 39.2 & 46.4 & 41.18 & 9 & .000 & 3 \\
\hline Teaching strategies B5 & 3.95 & .82 & $\ldots$ & 3.9 & 24.9 & 43.6 & 27.6 & & & & 3 \\
\hline Goal setting A6 & 4.03 & .81 & .. & 3.9 & 19.9 & 45.3 & 30.9 & 77.23 & 12 & .000 & 3 \\
\hline Goal setting B6 & 3.67 & .91 & 1.7 & 6.1 & 34.8 & 37.8 & 19.9 & & & & 4 \\
\hline Setting challenge A7 & 3.86 & .69 & 1.1 & 5.5 & 24.9 & 43.1 & 25.4 & 132.60 & 16 & .000 & 4 \\
\hline Setting challenge B7 & 3.60 & .96 & 3.3 & 5.5 & 37.0 & 35.4 & 18.8 & & & & 4 \\
\hline Monitor changes A8 & 3.84 & .90 & 1.1 & 3.9 & 31.5 & 36.5 & 27.1 & 146.19 & 16 & .000 & 4 \\
\hline Monitor changes B8 & 3.55 & .92 & 2.2 & 8.3 & 37.0 & 37.0 & 15.5 & & & & 4 \\
\hline Trying to solve the problem A9 & 4.09 & .77 & .. & 2.8 & 17.1 & 48.1 & 32.1 & 100.24 & 9 & .000 & 3 \\
\hline Trying to solve the problem B9 & 3.93 & .87 & $\ldots$ & 5.0 & 26.5 & 38.1 & 30.4 & & & & 3 \\
\hline Work cooperatively A10 & 4.29 & .80 & .6 & 1.7 & 13.3 & 37.0 & 47.5 & 215.29 & 16 & .000 & 4 \\
\hline Work cooperatively B10 & 4.8 & .93 & 1.1 & 3.9 & 21.5 & 32.0 & 41.4 & & & & 4 \\
\hline Individualization $\mathrm{A} 11$ & 3.85 & .91 & 2.2 & 5.0 & 22.1 & 46.4 & 24. & 199.67 & 16 & .000 & 4 \\
\hline Individualization B11 & 4 & .89 & 1.1 & 6.6 & 29.8 & 42.0 & 20.4 & & & & 4 \\
\hline Sense of belonging A12 & 4.16 & .81 & .6 & 1.7 & 18.2 & 39.8 & 39.8 & 198.45 & 16 & .000 & 4 \\
\hline Sense of belonging B 12 & 3.95 & .91 & 1.1 & 3.9 & 25.4 & 37.6 & 32.0 & & & & 4 \\
\hline
\end{tabular}


Based on table 3, in terms of item one (A), making the instruction clear one (.6\%) out of 181 claimed not important at all and twelve (6.6\%) stated fairly important and sixty-six (36.5\%) asserted important, and finally, $102(56.4 \%)$ claimed very important. The sum of important and very important is $168(92.9 \%)(\mathrm{M}=4.48$, $\mathrm{SD}=.67 ; \mathrm{R}=4)$. In line with table 3 , in terms of item one $\mathrm{B}$, how often teachers make their instructions clear, five $(2.8 \%)$ asserted hardly and seventeen (9.4\%) stated sometimes and sixty-eight (37.6\%) expressed often and 91 $(50.3 \%)$ remarked very often and the sum of often and very often is $159(87.9 \%)(\mathrm{M}=4.35, \mathrm{SD}=.76 ; \mathrm{R}=3)$. Moreover, a Chi-Square was run to determine if there is a significant difference between the instructors' knowledge and practice of mediation, with this item $\mathrm{c}^{2}(1, \mathrm{~N}=181)=82.339, p=.000<.05$ shows that there is a significant difference between instructors in terms of their knowledge of clear instruction and practice of clear instruction.

According to table 3, regarding item two A, which intends to measure whether the participants consider important to tell the learner why they are about to do an activity or not, one (.6\%) stated not at all important and seven $(3.9 \%)$ claimed hardly and forty-three (23.8\%) claimed fairly and eighty-five (47.0\%) believed important and forty-five $(24.9 \%)$ believed that it is very important and the sum of important and very important is 130 $(71.9 \%)(\mathrm{M}=.91, \mathrm{SD}=.82 \% ; \mathrm{R}=4)$. In line with table 3, in respect to item two $\mathrm{B}$ reason of doing an activity, one $(.6 \%)$ stated never and ten $(5.5 \%)$ asserted hardly and fifty-four (29.8\%) expressed sometimes and sixty-seven $(37.0 \%)$ remarked often and forty-nine (27.1\%) stated very often and the sum of often and very often is 116 $(64.1 \%)$ moreover, $(\mathrm{M}=3.84, \mathrm{SD}=.90 ; \mathrm{R}=4)$. With this item $\mathrm{c}^{2}(2, \mathrm{~N}=181)=260.143, p=.000<.05$ there is a significant difference between the sum of important and very important which encompasses $71.9 \%$ of those who believe it is important to tell their learners why they are to do the activity and the sum of often and very often which form $64.1 \%$ of the participant that really tell the learner why they are about to do an activity.

In item three A, explaining to their learners how to transfer the learning activity in future, six (3.3\%) stated hardly important and thirty-nine $(21.5 \%)$ claimed fairly important and eighty-nine (49.2\%) believed important and forty-seven $(26.0 \%)$ asserted very important and the sum of important and very important is $136(75.2 \%)$ $(\mathrm{M}=3.97, \mathrm{SD}=.78 ; \mathrm{R}=3)$. In item three $\mathrm{B}$, explaining to the learners how to transfer the learnt in future, nine $(5.0 \%)$ claimed hardly and fifty (27.6\%) stated sometimes and seventy-six (42.0\%) asserted often and forty-six $(25.4 \%)$ very often and the sum of often and very often is $122(67.4 \%)(\mathrm{M}=3.87, \mathrm{SD}=.84 ; \mathrm{R}=3)$. With this item $\mathrm{c}^{2}(3, \mathrm{~N}=181)=112.886, p=.000<.05$ there is a significant difference between $\operatorname{sum}(75.2 \%)$ of those who think it is important and very important to explain how to convey the learnt and acquired experience in their future learning and the sum $(67.4 \%)$ of those who often and very often explain to their learners how to transcend their experience and bridge them.

With regard to item four A, developing feeling of confidence in the learners, two (1.1\%) claimed hardly important and sixteen $(8.8 \%)$ claimed fairly important and sixty-five $(35.9 \%)$ of them claimed important and ninety-eight $(54.1 \%)$ claimed very important and the sum of important and very important is $163(90 \%)(\mathrm{M}=$ 4.43, $\mathrm{SD}=.70 ; \mathrm{R}=3$ ). Regarding item four $\mathrm{B}$, how often they help their learners develop feeling of confidence, three (1.7\%) stated hardly and 28 (15.5\%) claim sometimes and $73(40.3 \%)$ stated often and $77(42.5 \%)$ stated very often and the sum of often and very often $150(82.8 \%)(\mathrm{M}=4.23, \mathrm{SD}=.77 ; \mathrm{R}=3)$. With $\mathrm{c}^{2}(4, \mathrm{~N}=181)=$ 26.953, $p=.001<.5$, there is a significant difference between item four A and B in terms of their knowledge and practice and between the sum of important and very important $90 \%$ with the sum of often and very often $82.8 \%$.

As indicated in the table, in terms of item five A, which related to teaching strategies to learners, one (.6\%) claimed it is hardly important and twenty-five (13.8\%) believed fairly important and seventy-one (39.2\%) claimed it is important and eighty-four (46.4\%) believed very important and the sum of important and very important is $155(85.6 \%)(\mathrm{M}=4.31, \mathrm{SD}=.72 ; \mathrm{R}=3)$. In item five $\mathrm{B}$, teaching strategies to learners, seven (3.9\%) stated hardly and forty-five (24.9\%) believed sometimes and seventy-nine (43.6\%) claimed often and fifty $(27.6 \%)$ asserted very often. The sum of often and very often is $130(71.2 \%)(\mathrm{M}=3.95, \mathrm{SD}=.82 ; \mathrm{R}=3)$. With $\mathrm{c}^{2}$ 
Tahriri, A. \& Rezaee-Manesh, N.

$(5, \mathrm{~N}=181)=41.175, p=.000<.05$, it shows that there is a significant difference between the sum of important and very important which form $85.6 \%$ with the sum of often and very often which consist $71.2 \%$; therefore, there exists significant difference between the teachers' knowledge of strategy teaching and practice of it in their classroom.

Regarding item six A which is related to goal setting, seven (3.9\%) claimed hardly important and thirty-six (19.9\%) claimed fairly important and eighty-two (45.3\%) believed important and fifty-six (30.9\%) claimed very important and the sum of important and very important is $138(76.2 \%)(\mathrm{M}=4.03, \mathrm{SD}=.81 ; \mathrm{R}=3)$. As it is illustrated in the table, in respect to item six B that aims to measure how often the participants teach the learners to set their goals, three $(1.7 \%)$ believed never and eleven $(6.1 \%)$ claimed hardly and sixty-three (34.8\%) believed sometimes and sixty-eight (37.6\%) asserted often and thirty-six (19.9\%) claimed very often and the sum of often and very often is $104(57.5 \%)(\mathrm{M}=3.67, \mathrm{SD}=.91 ; \mathrm{R}=4)$. With $\mathrm{c}^{2}(6, \mathrm{~N}=181)=77.233, p=.000$ $<.05$, it reveals that there is a significant difference between $76.2 \%$ of the sum of important and very important with $57.5 \%$ of the sum of often and very often meanwhile the difference between the participants' knowledge of goal setting and practice of it in their classroom is significant as well.

In terms of item seven A which aims to assist learners to set their own challenge to meet, two (1.1\%) claimed not at all important and ten (5.5\%) claimed hardly important and forty-five (24.9\%) claimed fairly important and seventy-eight $(43.1 \%)$ believed important and finally, forty-six $(25.4 \%)$ claimed very important and the sum of important and very important is $124(68.5 \%)(\mathrm{M}=3.86, \mathrm{SD}=.89 ; \mathrm{R}=4)$. With respect to item seven $\mathrm{B}$ which intends to investigate how often the participants help their learners to set challenge for themselves, six $(3.3 \%)$ claimed never and ten (5.5\%) hardly and sixty-seven (37.0\%) asserted sometime and sixty-four $(35.4 \%)$ remarked often and finally thirty-four (18.8\%) claimed very often and the sum of often and very often is $98(54.2 \%)(\mathrm{M}=3.60, \mathrm{SD}=.96 ; \mathrm{R}=4) . \mathrm{c}^{2}(7, \mathrm{~N}=181)=132.598, p=.000<.05$ shows that $68.5 \%$ sum of important and very important is significantly different from $54.2 \%$ sum of often and very often and thus, there is a significant difference between the participants' knowledge and beliefs of challenge setting and their practice of it in their classes.

In terms of item eight $\mathrm{A}$ which aims to measure how important it is to help the learner to monitor the changes in themselves, two (1.1\%) stated not at all important and seven (3.9\%) claimed it is hardly important and fifty-seven $(31.5 \%)$ claimed fairly important and sixty-six (36.5\%) claimed important and forty-nine (21.1\%) asserted very important and the sum of important and very important is $115(57.6 \%)(\mathrm{M}=3.84, \mathrm{SD}=.90 ; \mathrm{R}=4)$. In terms of item eight B, monitoring changes in themselves, four (2.2\%) believed never and fifteen (8.3\%) claimed hardly and sixty-seven (37.0\%) asserted that they sometimes and sixty-seven (37.0\%) remarked often and twenty-eight $(15.5 \%)$ believed very often and the sum of often and very often is $95(52.5 \%)(M=3.55$, $\mathrm{SD}=.92 ; \mathrm{R}=4)$. With the item $\mathrm{c}^{2}(8, \mathrm{~N}=181)=146.185, p=.000<.05$ reveals that there is a significant difference between the sum $57.6 \%$ of important and very important and the sum $52.5 \%$ of the often and very often and thus the difference between learners' knowledge and beliefs with their real practice in their classes is significant, too.

With regard to item nine A, which aims to investigate how important is to help learners persist to solve the problem, five $(2.8 \%)$ claimed it is hardly and thirty-one (17.1\%) believed fairly important and eighty-seven $(48.1 \%)$ remarked important and fifty-eight (32.0\%) believed very important and the sum of important and very important is $145(80.1 \%)(\mathrm{M}=4.09, \mathrm{SD}=.77 ; \mathrm{R}=3)$. Regarding item nine $\mathrm{B}$, keeping on attempt to find solution to the problems, nine $(5.0 \%)$ claimed hardly and forty-eight $(26.5 \%)$ claimed sometimes and sixty-nine $(38.1 \%)$ believed often and fifty-five (30.4\%) claimed very often and the sum of often and very often is $124(68.5 \%)(\mathrm{M}=$ $3.93, \mathrm{SD}=.87 ; \mathrm{R}=3)$. With the item $\mathrm{c}^{2}(9, \mathrm{~N}=181)=100.235, p=.000<.05$ shows that $80.1 \%$ of the sum of important and very important is significantly different from $68.5 \%$ of often and very often as a result, participants' knowledge and beliefs of persistence in finding solution and their practice in side their classes are significantly different. 
The relationship between EFL instructors' knowledge of mediation and their classroom practice

In item ten $\mathrm{A}$ that measures how important they think to teach the learners to cooperate, one $(.6 \%)$ believed it is not at all important and three (1.7\%) of them claimed hardly important and twenty-four (13.3\%) believed fairly important and sixty-seven (37.0\%) believed important and eighty-six (47.5\%) believed very important and the sum of important and very important is $153(84.5 \%)$, and $(\mathrm{M}=4.29, \mathrm{SD}=.80 ; \mathrm{R}=4)$. Regarding item ten B, teaching learners to work cooperatively, two (1.1\%) believed never and seven (3.9\%) claimed hardly and thirty-nine (21.5\%) remarked sometimes and fifty-eight $(32.0 \%)$ believed often and seventy-five (41.4\%) claimed very often and the sum of often and very often is $132(73.4 \%)$, and $(\mathrm{M}=4.08$, $\mathrm{SD}=.93 ; \mathrm{R}=4)$. With the item $\mathrm{c}^{2}(10, \mathrm{~N}=181)=215.293, p=.000<.05$ shows that there is a significant difference between $84.5 \%$ the sum of important and very important and $73.4 \%$ which is the sum of often and very often; therefore, between the participants' beliefs and knowledge of teaching cooperation and their practice in their classes, there exists a significant difference as well.

Regarding item eleven A, developing individuality, four (2.2\%) claimed not at all important and nine (5.0\%) believed hardly important and forty (22.1\%) claimed fairly and eighty-four (46.4\%) stated important and forty-four (24.3\%) believed very important and the sum of important and very important is 128 which equals $72.7 \%$ of the whole participants, and $(\mathrm{M}=3.85, \mathrm{SD}=.91 ; 4)$. Regarding item eleven $\mathrm{B}$, two $(1.1 \%)$ believed never and twelve $(6.6 \%)$ claimed hardly and fifty-four (29.8\%) believed sometimes and seventy-six (42.0\%) believed often and thirty-seven (20.4\%) believed very often and the sum of often and very often is $113(62.4 \%)(\mathrm{M}=3.74$, $\mathrm{SD}=.89 ; \mathrm{R}=4)$. With the $\mathrm{c}^{2}(11, \mathrm{~N}=181)=199.666, p=.000<.05$ reveals that there is a significant difference between the sum of important and very important which consist $72.7 \%$ of participants and the sum of often and very often that encompass $62.4 \%$ and thus, the difference between belief in establishment of individuality and its practice in the class is significant.

Regarding item twelve A that investigates how important sense of belonging is, one (.6\%) claimed not at all important and three $(1.7 \%)$ believed hardly important and thirty-three (18.2\%) believed fairly important and seventy-two (39.8\%) believed important and seventy-two (39.8\%) believed very important and the sum of important and very important is $144(79.6 \%)$ and $(\mathrm{M}=4.16, \mathrm{SD}=.81 ; \mathrm{R}=4)$. In item twelve $\mathrm{B}$, two $(1.1 \%)$ believed never and seven (3.9\%) claimed hardly and forty-six (25.4\%) believed sometimes and sixty-eight (37.6\%) believed often and finally, fifty-eight (32.0\%) claimed very often and the sum of often and very often is $126(69.6 \%)$ and $(\mathrm{M}=3.95, \mathrm{SD}=.91 ; \mathrm{R}=4)$. With $\mathrm{c}^{2}(12, \mathrm{~N}=181)=215.293, p=.000<.05$ shows that there is a significant difference between $79.6 \%$ the sum of important and very important and $69.6 \%$ the sum of often and very often and thus, the difference between participants' knowledge and beliefs of sense of belonging and its practice is significant as well.

\subsection{Results of Oral interview with Institute Teachers}

\section{Table 4}

Significance of the Task in the Perspective of Institute Teachers

\begin{tabular}{llcc}
\hline \multicolumn{1}{c}{ Factors/Q1 } & Frequency & Percent \\
\hline 1 & Making the task significant & 16 & $100 \%$ \\
2 & Making the task significant will lead to an increase in motivation and learning; & 16 & $100 \%$ \\
3 & Engagement of learners makes the task significant; & 5 & $31.25 \%$ \\
4 & Explanation about the task makes it significant; & 5 & $31.25 \%$ \\
5 & Talking about the purpose makes the task significant. & 4 & $25 \%$ \\
\hline
\end{tabular}

Based on table 4, all the institute teachers believed that tasks should be made significant and regarding influence of task on learners' motivation and learning, all the institute teachers $(100 \%)$ claimed that it would increase them. In addition, $31.25 \%$ of institute teachers stated that engagement of learners makes the task significant and $31.25 \%$ of them too, believed that teachers' explanation about the task increases the significance and finally, $25 \%$ of institute teachers asserted that talking about purpose would lead to significance. A female teacher in Kish institute claimed: 
"By explaining about the importance of task in the process of learning and by providing opportunity to practice the task and to apply it and purposeful teaching and learning, I make the task significant and significance of the task increases the motivation and learning”.

\section{Table 5}

Transcendence in the View of Institute Teachers

\begin{tabular}{|c|c|c|c|}
\hline & Factors/Q2 & Frequency & Percent \\
\hline 1 & Possibility of Transcendence & 16 & $100 \%$ \\
\hline 2 & Using authentic and real life materials & 8 & $50 \%$ \\
\hline 3 & Making the task interactive & 7 & $43.75 \%$ \\
\hline 4 & Bridging the known to unknown & 6 & $37.5 \%$ \\
\hline 5 & Use of films, pictures, and other materials & 3 & $16.75 \%$ \\
\hline
\end{tabular}

In line with table 5, all the institute teachers (100\%) believed that transcendence is possible. To make transcendence possible, $50 \%$ of institute teachers stated that they utilize real and authentic materials in order to improve transcendence. Meanwhile, $43.75 \%$ of them asserted that they foster transcendence through making the task interactive, and $37.5 \%$ of institute teachers remarked that they bridge the known to unknown in order to boost transcendence. Eventually, $16.75 \%$ of institute teachers stated that they utilize aiding materials such as films and pictures to burgeon transcendence in the learners. Regarding transcendence one female teacher noted:

"Transcendence is possible. I believe students should know what they are learning for. Again, I think if the purpose is focused, and if students can match what they are learning to communication beyond the classroom, they can transcend. This is the teacher who makes the balance between the classroom communication and the real life. After learning linguistic requirement, the students should be placed in situations to practice what they leant in their class".

\subsection{Results of Oral Interview with University Instructors}

\section{Table 6}

Significance in the Idea of University Instructors

\begin{tabular}{llcc}
\hline \multicolumn{1}{c}{ Factors/Q1 } & Frequency & Percent \\
\hline 1 & Use of real world materials & 8 & $40 \%$ \\
2 & Task's being significant, motivation and learning increase & 13 & $65 \%$ \\
3 & Creating goal and purpose & 8 & $40 \%$ \\
4 & Explaining the role task would play in the learners' life & 5 & $25 \%$ \\
\hline
\end{tabular}

According to table 6, $40 \%$ of university teachers stated that they apply real world materials to promote significance of the task, and $65 \%$ of them noted that significance of task increases the motivation and learning. Moreover, $40 \%$ of university teachers believed that creating purpose will culminate in significance of the task and finally, $25 \%$ of them stated that explaining in terms of the role that the task play in learners' future life boost significance of the task. Regarding significance, one male instructor being 35 years old and with 12 years of experience in Tehran stated that:

"To make a task significant, first of all, I try to make the task seem fun and constructive to the learners. I also encourage them to feel the improvement in the accomplishment of the task. Regarding motivation and learning, the setting whether institute, school, or university will be a matter and on the whole, in my idea, significance, importance, and meaningfulness increase their learners' motivation and learning but learners in institutes carry motivation with themselves". 
The relationship between EFL instructors' knowledge of mediation and their classroom practice

Table 7

Transcendence in the View of University Teachers

\begin{tabular}{llcc}
\hline \multicolumn{1}{c}{ Factors/Q2 } & Frequency & Percent \\
\hline 1 & Transcendence is possible & 19 & $95 \%$ \\
2 & Real situation and real task & 17 & $85 \%$ \\
3 & Explaining to the learners how to transfer & 5 & $25 \%$ \\
4 & Helping them to apply their learnt & 7 & $35 \%$ \\
5 & Doing needs assessment to make the task relevant & 4 & $20 \%$ \\
\hline
\end{tabular}

Based on table 7, $95 \%$ of university teachers stated that transcendence is possible. To this end, $85 \%$ of them claimed that they apply real situation and task to do so. Furthermore, $25 \%$ of them stated that they explain to their learners how to transfer, and $35 \%$ of them noted that they help their learner convey their learnt, and finally, $20 \%$ of the university teachers believed that they do needs assessment in order to find relevant task. In terms of transcendence, a male instructor being 38 years old with 20 years of teaching claimed that:

"Yes, it is completely possible to transfer the learning to real context through making practice. I mean when we teach the learners a dialog or any learning tasks, it is better to tell them to use it and to converse with other people. He should remember that practice makes a man perfect".

\subsection{Results of Oral Interview of Junior High School Teachers}

\section{Table 8}

Significance of the Task in the Idea of Junior High School Teachers

\begin{tabular}{llcc}
\hline \multicolumn{1}{c}{ Factors/Q1 } & Frequency & Percent \\
\hline 1 & Use explanation in order to disambiguate & 10 & $58.82 \%$ \\
2 & Motivation and learning increase & 16 & $94.11 \%$ \\
3 & Availability of teachers to learners lead to significance of the task & 2 & $11.76 \%$ \\
\hline
\end{tabular}

As table 8 shows, $58.82 \%$ of junior teachers stated that explanation and disambiguation help them make the task significant, and $11.76 \%$ of them claimed that they try to be available to learners in order to increase the significance of the task, and finally $94.11 \%$ of them noted that significance of the task will promote leaners' motivation and learning. Regarding significance of the task, one female teacher being 38 and 14 years of teaching in junior school of Somesara stated that:

"I explain to the students that the task you are going to do is very important and I also explain to them how they use the task in real situations. Sometimes there is an important point in the task that they should remember for final examination. I think if a teacher convinces the learners why they should the task, the learners' motivation and learning will increase and then his or her learning will improve as well".

\section{Table 9}

Transcendence in the View of Junior High School Teachers

\begin{tabular}{llcc}
\hline & \multicolumn{1}{c}{ Factors/Q2 } & Frequency & Percent \\
\hline 1 & Transcendence is possible & 15 & $88.23 \%$ \\
2 & Relevant of classroom activity to outside classroom & 5 & $29.41 \%$ \\
3 & Creating real world context & 4 & $23.52 \%$ \\
4 & Amount of time allocation on the task & 2 & $11.76 \%$ \\
5 & Teachers explanation how to apply & 2 & $11.76 \%$ \\
\hline
\end{tabular}

Based on table $9,88.23 \%$ of the junior teachers stated that transcendence is possible. To make it possible, $29.41 \%$ of them claimed that they relate classroom activity to outside the classroom, and $23.52 \%$ of them stated that they create real word context to facilitate transcendence. Moreover, $11.76 \%$ of junior teachers asserted that teachers' time allocation on the task and their explanation how to transfer will boost transcendence. A male 
Tahriri, A. \& Rezaee-Manesh, N.

teacher being 42 years old and 23 years of teaching in junior school of Fouman stated that:

"I think it is possible to transcend but it depends on the students' interest. Some students are interested to use what they learn in real situation and some are not. To improve transcendence, I use real materials such as films, pictures, and also refer them to internet and encourage them to relate what they learn to what they have learnt".

\subsection{Results of Oral Interview of Senior High School Teachers}

\section{Table 10}

Significance of the Task in the Idea of Senior High School Teachers

\begin{tabular}{llcc}
\hline & \multicolumn{1}{c}{ Factors/Q1 } & Frequency & Percent \\
\hline 1 & Significance of task increases the motivation and learning & 19 & $100 \%$ \\
2 & Real world materials lead to significance & 5 & $26.31 \%$ \\
3 & Adjusting levels and relevance of the task to learners' level & 4 & $21.05 \%$ \\
4 & Arousing learners' motivation & 4 & $21.05 \%$ \\
5 & Using indirect and direct strategies to increase significance & 5 & $26.31 \%$ \\
\hline
\end{tabular}

According to table 10, all senior school teachers (100\%) stated that significance of task increases learners' motivation and learning, and to make a task significant, $26.31 \%$ of them stated that they apply real world materials. $21.05 \%$ of them remarked that arousing learners' interest and adapting levels and relevance of the task to learner' level will culminate in significance and finally, $26.31 \%$ of them believed that they utilize both direct and indirect strategies to burgeon significance. In regard with significance of the task, one male teacher being 45 and 25 years of teaching in Masal stated that:

“Task should be at the level of the students' linguistic and communicative knowledge. That is slightly above the students' present level. By using different techniques such as games, problem solving, circumlocution and so on I try to make the task meaningful and comprehensible and in this case students will learn more and become motivated and they will participate in classroom activities more".

\section{Table 11}

Transcendence in the Idea of Senior High School Teachers

\begin{tabular}{llcc}
\hline \multicolumn{1}{c}{ Factors/Q2 } & Frequency & Percent \\
\hline 1 & Transcendence is possible & 15 & $78.94 \%$ \\
2 & Transcendence is impossible & 4 & $21.05 \%$ \\
3 & Creating chance to use & 10 & $52.63 \%$ \\
4 & Real world materials & 8 & $42.10 \%$ \\
5 & Talking about the usage of task in the future & 5 & $26.31 \%$ \\
\hline
\end{tabular}

In line with table $11,78.94 \%$ of senior teachers stated that transcendence is possible and 21.05 of them asserted that it impossible. To transcend, 52.63 of them remarked that they create chance to use the learnt and $42.10 \%$ of them stated that they apply real world materials to facilitate transcendence, and finally $26.31 \%$ of them believed that teachers' talk regarding task application in future will increase transcendence. One female teacher being 38 and with 10 years of teaching in senior school of Rasht stated that:

"As you may concern, English is considered as foreign language in Iranian context so it is not easy to make a connection with real life. In order to bridge the gap between classroom atmosphere [artificial one] and real life, it would be plausible to allow opportunity to communicate freely and allow them for free communication. Suggesting the learners to read, write, and listen for pleasure would also be beneficial in developing learners' transcendence. Thus, in spite of difficulty, it is not impossible". 


\section{Discussion and Conclusions}

RQ1. Is there any relationship between EFL teachers' knowledge of mediation and their classroom practice?

Table 3 indicates that there is a strong relationship between EFL instructor' knowledge of mediation and their practice in their classes because p-value in all twelve items of knowledge and practice is less than alpha level $(p=.000<.05)$; therefore, in response to research question one, according to Chi-square analysis; there exists a relationship between EFL instructors' knowledge and practice. The findings of the present research on the basis of descriptive statistics and Chi-square reveal that not only Iranian instructors have knowledge of mediative features, but also they practice their knowledge of mediation in their classes, and this finding is not in line with Cheng' s $(2011,2012)$ findings which indicated that instructors in China are unable to do their mediative role perfectly due to their misconception regarding mediation theory, and such misconceptions lead to ready-knowledge transmission which is in contradiction with principle of mediation learning experience.

Although instructors in Iranian context have knowledge in terms of mediative features and they too, practice their knowledge in their settings, their knowledge and practice pertaining mediative features are not distributed equally. As such, some mediative features such as making the instruction clear, teaching the strategies the learners need, teaching the learners to work cooperatively, developing a sense of belonging in the learners, helping the learners keep on trying to solve the problems, and helping them set their own goals were known and practiced more inside their classes; however, as Chang's (1993) and Yang's (2002) study indicated Iranian EFLTs knowledge of mediative features and their practices in their classes are not in total harmony and this means that in spite of having knowledge and practicing inside their classes, there exist mismatch in this regard. This mismatch between knowledge and practice is in line with Segal's (1996) perspectives based on which he claimed that there always exists a mismatch between what the teachers know [their knowledge] and what they do inside their classes [their practices], and in his view this is not unnatural.

Regarding variation in the application of mediative features, in line with Schunk (2000) and William and Burden $(1997,2000)$ learners' age, gender, level, and cultural difference have an impact on instructors' option in terms of which one to apply. The results of the present study are not in line with Hosseini' s (2007) finding on the basis of which he stated that Iranian school is run through traditional methods such grammar translation and audio-lingual method and interaction is a missing link in EFL classes.

RQ2. What is the relationship between making a task significant and motivation in the perspectives of EFL instructors in different settings in Iran?

In response to RQ2, instructors in Iran stated that there is a direct relationship between significance of a task and increase of motivation but in this regard, all institute and senior high school teachers asserted that significance increases the motivation and learning, while junior and university are in second and third position. In terms of how to make a task significant, engagement of the learners, explanation, and talking about the purpose of the task were suggested by institute teachers while university teachers stated that they utilize strategies such as real world materials, creating goals and purpose, and explaining the role the task play in learners' future life. In terms of creating goal and purpose, both institute and university teachers claimed that they apply but university teachers focus more on the use of goal to make a task significant. Senior school teacher believed that they use real world material, adjust the task to the learners' levels, arouse learners' motivation, and use direct and indirect strategies to improve significance.

Like university teachers, the senior school teachers believe in the use of real world materials but university teachers claimed that they apply more than senior school teachers, and the variation in the use of different strategies results from difference in terms of context, gender, age, level and this is in line with what Williams and Burden (1997) and Schunk (2000) stated. Junior high school teachers claimed that they use explanation and they avail themselves to the learners to make the task significant. In comparison to three other groups of teachers, junior school teachers utilize more explanation. 
Tahriri, A. \& Rezaee-Manesh, N.

RQ3. What do EFL instructors in Iran think of transcendence?

In response to the third research question, EFL instructors in four different settings stated that transcendence is possible but in terms of frequency of teachers in each setting variation exists, and that might results from the type of beliefs they have pertaining their contexts, learners, and even themselves and in some cases the type of expectation and goals that the parents and stakeholders determine, will have an impact on the extent of transcendence. As such, the variation seems logical. To rank them on basis of the percentage, institute teachers $(100 \%)$ are the first and then university (95\%), junior (88\%), and senior teachers (78\%) ranked second, third, and fourth. Regarding how to facilitate transcendence, instructors in four settings stated that they apply real world and authentic materials but in this regard, university teachers $(85 \%)$ are the first, and institute, senior, and junior teachers possess other ranks. Bridging the known to unknown, explaining how to transfer, helping learners transfer, doing needs assessment to determine how to apply, time allocation on a task, providing chance to use, talking about the usage of task in learners' future life are factors that the participating instructors considered important in fostering transcendence.

\subsection{Pedagogical Implications}

The present study probed to what extent EFL instructors have knowledge of mediation and how often they practice their knowledge of mediation in their classes. The findings revealed that not only EFL instructors in Iran have knowledge of mediation, but also they actualize their knowledge of mediation in their classes, but between the degree of knowledge and amount of practice, there exists a mismatch, and it means that their practice do not reflect their total knowledge of mediation. Results of oral interview of the participants in four different settings revealed that they utilize different factors and strategies in order to facilitate significance of the task to foster transcendence. Finally, the results revealed that transcendence is possible and motivation and learning increases due to significance. To conclude, based on results of close-ended questionnaire and oral interview, instructors in Iran are familiar with mediative knowledge and practice.

Having knowledge of mediation, its implementation, and teachers' belief in positive results can culminate in cognitive development of the learners and the most important thing regarding mediation theory is related to the fact that cognitive system of the human beings is not fixed and instead, it is modifiable and malleable. In fact, being aware of the importance of mediative knowledge and practice, teachers in different settings might attempt to apply mediative features more frequently in their context. In addition, learners of different abilities and potentials can benefit from teachers' instruction in a more efficient way. Considering the fact that range, rate, phase, and duration of intervention is highly important both in learners' learning and in teachers' time allocation, teachers' knowledge in terms of mediative features helps them to concentrate on those tasks in which learners need more support. Because of due investment and consideration, what is required for effective teaching and learning would be achieved and as such, it might lead to a prosperous condition for ideal education. In addition, to fill the gap between knowledge and practice requires the provision of more appropriate teacher training courses from a practical point of view.

Finally, nobody in the area of language learning and teaching, and designing curricula, and syllabi should be disappointed. Teachers in different settings are suggested that they distance themselves from the role of knowledge disseminators to that of enablers of learners. To make possible such modifications, the learning environment should stimulate feelings of competence, goal setting, significance, and challenge both for learners and teachers. 


\section{References}

Chang, C. W. (1993). An investigation into teachers' mediation with junior college students' learning English in Taiwan. Retrieved from http://nhcuer.lib.nhcue.edu.tw/bitstream/392440000Q/1049/1/10281991-200406-X-18-97-135-a.pdf

Cheng, X. (2011): Knowledge of mediation and its implementation among secondary school Cheng EFL teachers in China. Theory and Practice in Language Studies, 1(9), 1111-1121. http://dx.doi.org/10.4304/tpls.1.9.1111-1121

Cheng, X. (2012). Evaluation on EFL teacher role from the perspective of mediation: Case studies of China's secondary school classroom practices. International Review of Social Science and Humanistic, 3, 117-134.

Daniels, H. (Ed.). (1994). Charting the agenda: Educational activity after Vygotsky. London and New York: Routledge.

Feuerstein, R. (1980). Instrumental enrichment: An intervention program for cognitive modifiability. Baltimore, MD: Park University Press.

Feuerstein, R., \& Louis, F. (1990). Cognitive perspectives for counseling and psychotherapy. International Journal of Cognitive Education and Mediated Learning, 1(2), 143-150.

Feuerstein, R., \& Feuerstein, S. (1991). Mediation learning experience: Theoretical review. In R. Feuerstein, P. S. Klein \& A. J. Tannenbaum (Eds.), Mediated learning experience: Theoretical, psychosocial \& learning implications (pp. 3-51). London: Freund.

Hosseini, S. M. H. (2007). ELT in higher education in Iran and India: critical view. Language in India, 7, 1-11. Retrieved January 16, 2012 from http://www. languageinindia.comdec2007/eltinindiaandiran.pdf

Lantolf, J., \& S. Thorne. (2006). Sociocultural theory and the genesis of second language development. Oxford: Oxford University Press.

Schunk, D. H. (2000). Learning theories: An educational perspective ( $3^{\text {rd }}$ ed.). Upper Saddle River, NJ: Prentice Hall.

Segal, S. (1998). The role of contingency and tension in the relationship between theory and practice in the classroom. Curriculum Studies, 30(2), 199-206. http://dx.doi.org/10.1080/002202798183701

Seng, A. S. H., Pou, L. K. H., \& Tan, O. S. (2003). Mediated learning experience with children. Singapore: McGraw-Hill.

Sun, J. F. (2005). Evaluation on EFL teachers' roles from the perspective of social constructivism. Unpublished master's thesis, Henan Normal University, China.

Swain, M. (2000). The output hypothesis and beyond: Mediating acquisition through collaborative dialogue. In J. P. Lantolf (ed.), Sociocultural theory and second language learning (pp. 99-116). Oxford: Oxford University Press.

Ting, Y. (1987). Foreign language teaching in China: Problems and perspectives. Canadian and International Education, 16(10), 48-61.

Tzuriel, C. (2000). Dynamic assessment of young children: Educational and intervention perspectives. Educational Psychology Review, 12(4), 385-435. http://dx.doi.org/10.1023/A:1009032414088

Warren, P. (1995). An investigation into the use of task that develop both second language learning and thinking skill with children. Unpublished MED thesis. University of Exeter.

Williams, M. \& Burden, R. L. (1998). On Reuven Feuerstein. In D. Mendelsohn (ed.), Expanding our vision. Oxford: Oxford University Press.

Williams, M., \& Burden, R. L. (2000). Psychology for language teachers. A social constructivist approach. Cambridge: Cambridge University Press.

Vygotsky, L. (1978). Mind in theory: The development of higher psychological process. Cambridge, MA: Harvard University Press. (Original work published in 1930-33)

Yang, N. (2002). A study of prospective teachers' perceptions about mediation. English Teaching \& Learning, 
Tahriri, A. \& Rezaee-Manesh, N.

23(6), 79-100.

Yang, M. J. (2005). Roles shifting of EFL teachers in class. Primary and secondary school English Teaching and Research, 6, 9-12.

Ye, J. (2007). Adapting communicative language teaching approach to China's context. Sino-US Teaching, 4(10), 29-33. 